\title{
Linking Electronic Medical Records use to Physicians’ Performance: A contextual analysis
}

\author{
David D. Dobrzykowski ${ }^{\text {a† }}$, Monideepa Tarafdar ${ }^{\mathrm{b}}$
}

a Department of Supply Chain Management and Marketing Sciences, Rutgers Business School, Rutgers University, 1 Washington Park, Rm 958, Newark, NJ 07102-3122, ddobrzykowski@business.rutgers.edu

${ }^{\dagger}$ Corresponding author.

b Management Science Department, Lancaster University Management School, RmA42, Lancaster, LA1 4YX, UK, m.tarafdar@lancaster.ac.uk

David D. Dobrzykowski is an Assistant Professor in the Department of Supply Chain Management at Rutgers Business School (RBS) at Rutgers, the State University of New Jersey. He is also Co-Director of the M.S. in Healthcare Services Management program at RBS. He received his Ph.D. from the University of Toledo in 2010, where he later served as Director of the School for Healthcare Business Innovation and Excellence. His research investigates coordination in supply chains, focusing on healthcare. He has published in Decision Sciences, Journal of Operations Management, Journal of Supply Chain Management, Service Science, International Journal of Production Research, International Journal of Production Economics, Journal of Service Management among others. Prior to academe, he enjoyed a 13-year healthcare industry career, serving in CEO and VP roles.

Monideepa Tarafdar is Professor of Information Systems and Co-Director of the HighWire Doctoral Training Centre at Lancaster University (Management School), Lancaster, UK. Her research focuses on technology-enabled business innovation, the 'dark' side and productivity reducing impacts of pervasive technology use, technology in supply chains and healthcare operations, and technology reach into 'disconnected' (physically remote, people with special abilities or health conditions) populations. She received a doctorate in Management (specializations in Management Information Systems and Strategic Management) in 2002 from the Indian Institute of Management Calcutta. She has worked in engineering positions with AT\&T and Philips. She joined Lancaster University in 2013, prior to which she was at the University of Toledo, USA. Her research has been published or is forthcoming in, among others, Information Systems Research, Journal of Operations Management, Journal of MIS, Sloan Management Review, Decision Sciences Journal, Journal of Strategic Information Systems, Journal of IT, Information Systems Journal, Information and Management, DATABASE for Advances in Information Systems, International Journal of Operations and Production Management, International Journal of Production Economics and Communications of the ACM. 


\title{
Linking Electronic Medical Records use to Physicians’ Performance: A contextual analysis $^{\dagger}$
}

† The authors thank Professor Cheri Speier-Pero for her guidance as Editor-In-Chief, the Associate Editor, and anonymous reviewers for their encouragement and useful comments that aided the improvement of this article.

\begin{abstract}
Electronic Medical Records (EMR) studies have broadly tested EMR use and outcomes, producing mixed and inconclusive results. This study carefully considers the healthcare delivery context and examines relevant mediating variables. We consider key characteristics of: 1) interdependence in healthcare delivery processes, 2) physician autonomy, and 3) the trend of hospital employment of physicians, and draw on theoretical perspectives in coordination, shared values, and agency to explain how the use of EMR can improve physicians' performance. In order to examine the effects of physician employment on work practices in the hospital, we collected 583 data points from 302 hospitals in 47 states in the USA to test two models; one for employed and another for non-employed physicians. Results show that information sharing and shared values among healthcare delivery professionals fully mediate the relationship between EMR use and physicians' performance. Next, physician employment determines which mediating variable constitutes the pathway from EMR use to physicians’ performance. Finally, we highlight the impact of shared values between the hospital and physicians in enhancing information sharing and physicians’ performance, extending studies of these behaviors among network partners in industrial settings. Overall our study shows that EMR use should be complemented by processual (information sharing), social (shared values) and structural (physician employment) mechanisms to yield positive effects on physicians’ performance.
\end{abstract}




\section{INTRODUCTION}

Healthcare provider organizations (i.e., hospitals) in the USA are under substantial pressure to improve performance and it is commonly held that healthcare information technologies (HIT) - specifically electronic medical records (EMR) use - are an important solution (GAO, 2005; Smith, Bradley, Bichescu, \& Tremblay, 2013). However, appropriating benefits from EMR use has been inconsistent and in some cases negative outcomes have been reported (McCullough, 2010). For example, Cedars Sinai Medical Center invested \$34 million in an EMR system only to find that "physicians found that it took much, much longer to use the new computer system than did the same ordering with pen and paper... [and placed] severe limitations on their ability to make medical judgments,” (Smelcer, Jacobs-Miller, \& Kantrovich, 2009: p. 70). Similarly, Kaiser Permanente found that clinicians were taking 30 to 75 minutes longer per day to do their work with an EMR system (Scott, Rundall, Vogt, \& Hsu, 2005).

These industry examples raise two important issues facing hospital leaders; (1) appropriating benefits from technology use, and (2) coordinating with physicians to improve performance (ACHE, 2013). With regard to the former, while the federal government in the US has essentially mandated the 'meaningful use' of EMR via financial incentives/disincentives, achieving the expected performance improvements has been illusive (Smith et al., 2013). Regarding the latter, hospital performance is influenced to a great extent by the performance of the physicians practicing in the hospital (Ilie, Van Slyke, Parikh, \& Courtney, 2009; Sinha and Kohnke, 2009). Although hospitals make available facilities and staff for patient diagnosis and treatment, autonomous physicians, who may have different financial incentives than the hospital, are the chief source of medical decision-making affecting length of stay, resource utilization, and 
ultimately hospital performance (Field, Heineke, Langabeer, \& DelliFraine, 2014; Fredendall, Craig, Fowler, \& Damali, 2009).

The fact that performance improvements from EMR use are not uniformly achieved could signal that the benefits are contingent upon the context of use. IT usage results in positive impacts when there is a match between use and requirements of the context. In general, the impact of information technology use on beneficial performance outcomes is mediated by variables that appropriately characterize the context of use (Markus \& Tanis, 2000) and depends on complementary and supporting factors associated with use (Devaraj \& Kohli, 2000). Thus far however, research looking at the relationship between EMR use and performance outcomes (i.e., financial performance of hospitals) has focused on the broad association between them in a black box fashion, providing an opportunity to carefully consider particular characteristics of healthcare processes (Ben-Assuli \& Leshno, 2013; Poissant, Pereira, Tamblyn, \& Kawasumi, 2005; Smith et al., 2013). In addition, little is known, about how the use of EMR can improve the services provided by physicians (Jha et al., 2009). Thus, the objective of this paper is to examine how, and under what conditions, the use of EMR by healthcare delivery professionals (i.e., physicians, nurses, and hospital staff) in a hospital can be linked with improved physicians' performance in the hospital.

We address our research objective by developing hypotheses that consider two variables particularly important to the healthcare context - information sharing and shared values between physicians and hospital staff, as links between EMR use and physicians' performance. Considering that a substantial portion of physicians are independent, that is, not employed by the hospitals within which they practice (Bush, 2012), we examined its effect on the above relationships. We collected primary survey data to test the effects of observable organizational 
phenomena with respect to EMR use by healthcare professionals, in employed as well as nonemployed physicians. This procedure produced two datasets totaling 583 data points collected from 302 hospitals in 47 states in the USA. We test two models - one examining hypotheses for employed physicians ( $n=302)$, and a second for non-employed physicians ( $n=281)$ - using Structural Equation Modeling and make three important theoretical contributions. First, we show that under particular conditions, both information sharing and shared values between the physician and the hospital mediate the relationship between EMR use and physicians' performance, thus opening the somewhat intractable EMR - performance black box (Poissant et al., 2005). Second, our study reveals a role for physician employment by showing that it determines which of the two mediating variables constitute an 'active' pathway from EMR use to physicians' performance. Third, we examine the difficulties in achieving coordination through information sharing and highlight the impact of shared values between the hospital and physician in enhancing it, extending current studies that focus on the role of shared values among network partners in primarily industrial settings (e.g., Carey, Lawson, \& Krause, 2011; Villena, Revilla, \& Choi, 2011). Overall our study shows that EMR use should be complemented by processual (information sharing), social (shared values) and structural (physician employment) mechanisms to yield positive effects on physicians' performance. In doing so, we provide theoretical explanation for a particularly current and somewhat knotty issue for hospitals which are struggling to deal with the implications of physician autonomy (Boyer \& Pronovost, 2010) for EMR use.

\section{THEORY AND CONTEXTUAL BACKGROUND}

EMR use is defined as the extent to which a hospital's healthcare delivery professionals (i.e. doctors, nurses and staff) use electronic medical records systems for clinical documentation 
(Ash, Gorman, Seshadri, \& Hersh, 2004; Cutler, Feldman, \& Horowitz, 2005; Jha et al., 2009). We note here that the EMR use is its collective use by healthcare delivery professionals (physicians and staff of the hospital). System usage at the collective level is an organizational behavior (Masetti \& Zmud 1996, Devaraj \& Kohli 2003). It emerges when users of an application are affiliated with one another, when tasks require a number of individuals to coordinate their work and when the system has features that facilitate interdependence in the form of communication, common data storage, common workflows (Burton-Jones \& Gallivan 2007). In the healthcare context, users of EMR systems, that is, doctors and medical staff are affiliated through their medical cases and need coordination for delivering healthcare. EMR applications facilitate communication between physicians and medical staff, enable them to perform their tasks through system workflows and provide common data storage.

High variation exists in EMR use among hospitals (Dobrzykowski, 2012). This may be owing to the inconclusive findings from researchers as to the efficacy of EMR use. Some EMR studies indicate positive outcomes such as patient satisfaction (Queenan, Angst, \& Deveraj, 2011) and reduced costs (Ben-Assuli \& Leshno, 2013; Li \& Benton, 2006), while other studies report negative effects such as increased physician documentation time and workload and reduced reporting flexibility (Poissant et al., 2005; Lahiri \& Seidmann, 2012). Still other studies investigating EMR use and inpatient mortality and length of stay show little impact (Goh, Gao, \& Agarwal, 2011). Agarwal et al. (2010) provide a comprehensive literature review of health IT (and EMR) use and anticipated improvements.

Recent studies (e.g., Boyer \& Pronovost, 2010; Devaraj, Ow, \& Kohli, 2013) suggest, but do not elucidate why, lack of coordination in the healthcare delivery process may be a principal reason why EMR systems have failed to yielded unqualified benefits. Indeed, the literature does 
not adequately address the relationship between EMR use, coordination among healthcare delivery professionals, and physicians' services provided to patients in the hospital. In this section, we first draw from theories of interdependence to examine the requirement of coordination among physicians and hospital nurses/staff inherent in healthcare delivery processes, and use information processing theory to explain the role of information sharing as means to achieve coordination. We next describe barriers that might exist for information sharing among healthcare professionals and draw upon the concept of shared values between physicians and hospital staff as a means to increase information sharing. Third, we use an agency lens to suggest that physician employment might influence the relationship between EMR use, and information sharing and shared values.

\section{Coordination in Healthcare Processes}

Some key aspects characterize healthcare delivery processes. The exact content of tasks is not always known beforehand (Nembhard, Alexander, \& Ramanujam, 2009), as diagnosis involves standard procedures such as testing and also emergent activities involving back and forth between physicians and nurses/clinical staff (Tucker, 2004). The order of tasks may not be specified, but involve iterations among collecting data about patients, consultations among specialists, and diagnosis (Malone \& Crowston, 1994). Processes for a given patient-episode of healthcare delivery occur in different facilities (e.g. laboratories, hospital beds, imaging rooms) (Kenagy, Berwick, \& Shore, 1999; Boyer \& Pronovost, 2010), and professionals involved in diagnosis and treatment belong to multiple specializations with different bodies of knowledge (Leape \& Berwick, 2005). There are three consequences of these aspects. There is uncertainty (Galbraith, 1973), in that the precise information needed at the point of care delivery "action” is not always known. Next, there is differentiation (Lawrence \& Lorsch, 1976) in that multiple 
specializations of healthcare professionals can lead to differences in perceptions and points of view. Finally, there is interdependence (Thompson, 1967) between tasks, in the form of reciprocal (e.g. a physician's diagnosis is based on testing, medicine administration, and other bedside procedures executed by others), sequential (e.g. diagnosis based on appropriate tests being taken), or shared responsibility (Simatupang, Sandroto, \& Lubis, 2004; Sinha \& Kohnke, 2009) (e.g. multiple actors - physicians, nurses, medical technicians - are responsible for a shared work goal - patient diagnosis and cure). Practice commentary (e.g., Green, 2012; Buell, 2013) observes that as a consequence of inadequate coordination among healthcare professionals, important medical information is not available at the time of treatment, test results need to be replicated, protocols are not always followed, and contradicting procedures and medicines may be prescribed leading to poor clinical outcomes.

Information processing theory suggests that coordination through information sharing between process participants is required to address these three conditions (e.g., Galbraith 1973, Malone \& Crowston 1994). Specifically for healthcare delivery processes, which are emergent and require multiple specializations to interact, resolve differences (Simatupang et al., 2004), and develop a solution (Malone \& Crowston, 1994), coordination requires information shared among doctors, nurses and hospital staff (Coiera, 2000). Much of this information is complex, tacit, nonroutine, involves collation from different sources (Gittell \& Weiss 2004), and is not always present in EMR systems but is based on their outputs (Lahiri \& Seidmann, 2012). Information sharing is defined as the extent to which healthcare delivery actors communicate patient-care information, to one another (Paulraj, Lado, \& Injazz, 2008; Speier, Whipple, \& Closs, 2011). It is defined at the level of the collective of healthcare delivery actors and embodies their 
interactions with one another in the context of communicating patient information such as treatment plans.

\section{Barriers to Information Sharing and Shared Values}

There are a number of barriers to information sharing between healthcare delivery professionals. Inter-professional interactions (e.g., between physicians and nurses) are governed by an established hierarchy and often limited to routine-based sharing of information such as test results and medical charts (Nembhard et al., 2009). Further, given the large variety of specialties in healthcare, such interactions often occur among professionals possessing differing world views or values. Finally, physicians can have a stronger professional than organizational identification (Dobrzykowski, Callaway, \& Vonderembse, 2015) and often preferring autonomy to collaborative and collective approaches (Boyer \& Pronovost, 2010; Leape \& Berwick, 2005; Field et al., 2014).

The operations management literature provides a common cognitive approach described as shared norms/vision and compatible goals/objectives in the relationship between network partners (Krause, Handfield, \& Tyler, 2007; Carey et al., 2011; Villena et al., 2011). We draw from this idea to suggest that shared interpretations and systems of meaning (Nahapiet \& Ghoshal; 1998) between the physician and hospital provide a shared understanding regarding collective goals and can potentially lower barriers to information sharing between healthcare delivery professionals (Gittell, 2002). Shared values is defined as the extent of common beliefs, goals and views among physicians and the hospital staff regarding patient care (Huang \& Wang, 2013; Krause et al., 2007; Shah, Goldstein, Unger, \& Henry, 2008; Villena et al., 2011; Carey et al., 2011). It embodies a collective orientation held by healthcare delivery actors towards patient care such as a willingness to collaborate in treating patients. This would seem like an 
indisputably common objective, yet many times providers struggle to effectively collaborate due to behavioral barriers such as late arrivals of surgeons for example (Fredendall et al., 2009) or technical barriers such as discipline diversity and specialization (Nembhard et al., 2009).

\section{Agency in the Healthcare Context}

Traditionally, a physician has functioned as an “...owner-operator of his own ongoing firm” when providing services to patients in a hospital setting (McLean, 1989: p. 67). Indeed today, with only about $20 \%$ of all physicians being employed by the hospitals within which they provide services (Bush 2012), a majority of physicians may be considered to function as independent owner-operators. In the absence of physician employment, and hence of a contractual agreement bearing financial consequences between the physician and hospital, there is often little incentive for healthcare delivery professionals to coordinate their activities (Fredendall et al., 2009; Shah et al., 2008). Personal rather than the hospital's goals may guide their behavior (Huang \& Wang, 2013).

The idea of agency provides a relevant lens for understanding the relationship between the hospital and physicians (McLean, 1989; Dranove \& White, 1989; Schneller \& Smeltzer, 2006; Chang, 2011). An agent’s actions may not align with the principal’s goals when “ $\ldots$ a) the desires or goals of the principal and agent conflict and b) it is difficult or expensive for the principal to verify what the agent is actually doing,” (Eisenhardt, 1989: p. 58). With respect to the first, for many years, the relationship between a physician (i.e., agent) and a hospital (i.e., principal) involved the physician being granted privileges to admit and treat patients in the hospital, but receiving compensation for services from third party entities such as insurers (Ford \& Scanlon, 2007), resulting in the physician being positioned independent of the hospital, not necessarily with the same financial goals (McLean, 1989; Fredendall et al., 2009). From the 
point of view of the second, physicians' behavior and performance are difficult for the hospital to observe and measure, given the nature of their work (Goodale et al., 2008). Thus, managing physicians’ work practices and how they interact with hospital staff is complicated at best.

Recently therefore, physician employment has emerged as a mechanism to align physicians' goals and behaviors with the objectives of the hospital (Fink \& Hartzell, 2010). Employed (non-employed) physicians are those with whom the hospital has (does not have) a financial contractual relationship (Schneller \& Epstein, 2006; Fink \& Hartzell, 2010; Andrabi, 2012). This is rooted in the belief that by integrating the physicians they employ, hospitals can improve performance (Fink \& Hartzell, 2010). Physicians’ performance is defined as the extent to which admitting / attending physicians collectively provide dependable, timely, and appropriate services to patients in the hospital (Schneller \& Smeltzer, 2006; Reddy, Iwaz, et al., 2012). These are relevant dimensions of performance considering the principal-agent nature of the hospital-physician relationship given that if their financial incentives diverge, there is an opportunity for opportunistic behavior such as physicians rounding late to accommodate personal efficiency while delaying hospital processes (i.e., morning orders to the pharmacy).

\section{HYPOTHESES DEVELOPMENT}

Drawing on this theory background, Figure 1 shows our research hypotheses. H1 examines relationships among EMR use by healthcare delivery professionals, information sharing among them, and physicians' performance. H2 similarly examines relationships among EMR use by healthcare delivery professionals, shared values among them, and physicians' performance. $\mathrm{H} 3$ describes the role of shared values in influencing information sharing and physicians’ performance. 
Insert Figure 1 about Here

\section{The role of Information Sharing in translating EMR Use into Physicians' Performance}

Goh et al. (2011) suggest that rather than just the use of EMR, it is the work practices complementing EMR use that support physicians' superior performance. The IS literature highlights that collective IS use depends on the interactions or interdependencies among users that relate to the use of the system (Karsten, 2003), and that it results in group level outcomes, influenced in an emergent way by contextual factors such as system features, tasks and users (DeSanctis \& Poole 1984, Orlikowski 1996, Burton-Jones \& Gallivan 2007). Considering the collective use of EMR, key contextual factors include the EMR features such as the functionality to capture and store all patient information in a single database, in order to interact and coordinate with each other in carrying out healthcare delivery tasks. Such use enables healthcare delivery actors in the hospital to record current patient information useful in care delivery such as nursing assessments, problem lists, and a patients’ advanced directives (Jha et al., 2009), essentially transforming the EMR into a platform serving as the basis of information exchange among them (Prahalad \& Ramaswamy, 2004; AHRQ 2013).

EMR use keeps healthcare delivery actors apprised of key information, so that they can share details about relevant issues with each other (Wasko \& Faraj, 2005; Speier et al., 2011). Sobun (2002) suggests that health information systems are more effective when the clinical staff act as a 'consulting team' that participates in ongoing information sharing supported by EMR as opposed to a 'reporting shop' using the EMR system strictly for inputting patient information (Devaraj et al., 2013). Information sharing is thus an important embodiment of coordination among healthcare delivery professionals. It informs the environment within which physicians 
perform their work, allowing them to effectively create value (Vargo \& Lusch, 2004; Schmenner, VanWassenhove, Ketokivi, Heyl, \& Lusch, 2009). Outcomes from collective IS use often relate to the collective performance of key users (DeSanctis \& Poole 1984). In the context of EMR use, it is manifested in physicians' performance in terms of the overall services they provide to patients in the hospital. Indeed, adverse events such as medical errors have been linked to lack of communication and information sharing (The Advisory Board Company, 2014). We thus suggest that information sharing is a constructive link between EMR use and physicians’ performance.

Employment contracts influence the working relationship between the hospital and physicians (Schramko, 2007). For non-employed physicians we note two things. One, their agency relationship with the hospital is likely to be weak because of a lack of alignment of financial incentives; as such, they work with a high degree of autonomy (Dranove \& White, 1987) and are less likely to engage in information sharing with hospital staff. Two, lack of continuous physical presence in the hospital (Ford \& Scanlon, 2007) might make it difficult for them to share information with hospital staff. The EMR system addresses both these conditions. IT provides them with a platform to quickly access and share information with other clinicians in the hospital. By doing so, it boosts their extent of information sharing, thus strengthening the linking role of information sharing between EMR use and physicians’ performance.

We therefore hypothesize:

H1: Information Sharing mediates the relationship between EMR Use and Physicians' Performance for independent (non-employed) physicians.

\section{The role of shared values in translating EMR use into physicians' performance}

Particularities of collective system use manifest over time as users interact with the system and with one another within the context of use (Burton-Jones \& Gallivan, 2007). Such 
particularities potentially mediate the relationship between use and its outcomes (Orlikowski, 1996). Studies suggest that an important factor that determines the nature of these particularities here is the nature of affiliations that users have with one another (Lamb \& Kling, 2003). For employed physicians, given their strong agency relationship with the hospital (Fink \& Hartzell, 2010), they have a higher volume of interaction with the hospital's staff, greater allegiance to the hospital, and a higher level of alignment with its goals (Gordon, Gust, Kazzaz, \& Synder, 2011). Employed physicians' use of EMR is thus likely to be accompanied by greater interaction with nurses/staff, boosting collaborative efforts. That is, as access to useful information increases over time via EMR use (AHRQ, 2013), physicians are expected to recognize the system's importance as a key support resource in performing their work (Lahiri \& Seidmann, 2012), and develop strong shared values with the hospital. We thus suggest that for EMR use in hospitals, shared values between physicians and the hospital is an important contextual particularity that can have an instrumental mediating influence on the relationship between collective EMR use and physicians’ performance when physicians are employed.

EMR systems provide access to unified and consistent patient information, which is expected to aid physicians in clinical practice, thus indicating a possible positive influence on collective physicians' performance. However this is possible when the shared interpretation of the information by healthcare delivery actors is consistent and coherent and enables them to develop a common view of patient care, arriving at a shared vision when treating a patient (AHRQ, 2013). That is, the shared values between physicians and hospital staff are strong. We also note that shared values are effective in overcoming uncertainty (Fredendall et al., 2009) and leads to greater understanding of patient and hospital requirements on the part of the physician. It is useful in overcoming differentiation borne out of clinical specialization (Nembhard et al., 
2009), enabling healthcare delivery professionals to work as a team (Boyer \& Pronovost, 2010).

This leads to confidence in and mutual respect for one another's work (Shah et al., 2008;

Fredendall et al., 2009) and creating conditions suitable for mutual support. Shared values thus provide an overall enabling social environment for physicians to execute healthcare delivery tasks (Gittell et al., 2000) and are expect to improve physicians’ performance.

Given that EMR use strengthens shared values and shared values boosts physicians' performance we suggest that shared values is a mediator link in the relationship between EMR use and physicians’ performance.

We therefore hypothesize:

H2: Shared Values mediates the relationship between EMR Use and Physicians' Performance for employed physicians.

\section{Relationships among shared values, information sharing and physicians' performance}

As noted earlier, information asymmetries among healthcare delivery actors are a major barrier to improving their performance (Ford and Scanlon 2007). Shared values ought to enhance physicians' performance by enabling greater understanding of patient (and hospital) requirements on the part of physicians, by helping overcome differentiation borne out of clinical specialization (Boyer \& Pronovost, 2010) and by facilitating healthcare delivery professionals'

confidence in and mutual respect for one another's work (Shah et al., 2008; Fredendall et al., 2009).

In addition, shared values also enhance information sharing because they decrease the burden of coordinating work between actors, increases the efficiency of information diffusion among them (Nahapiet \& Ghoshal, 1998), and has been seen to lead to knowledge contribution in open source communities (Wasko \& Faraj, 2005). Shared values between the hospital and 
physicians allow healthcare professionals to find credibility, assurance and confidence in one another, which motivates timely and accurate information sharing (Dyer \& Singh, 1998; Carey et al., 2011). They beget commitment among nurses, doctors and staff, motivating "dense" interactions (Prahalad \& Ramaswamy, 2004; Villena et al., 2011) and enhancing information sharing with a common understanding of desired results and promotes information sharing (Hsu \& Sabherwal, 2012).

When goals and values of physicians and hospital staff are incongruent, interactions might lead to misinterpretations and conflict (Inkpen \& Tsang, 2005). “As misinterpretation and conflict intensifies, both parties can be expected to become dissatisfied, and to limit information sharing, resulting in negative effects on productivity and performance” (Krause et al., 2007: p. 532). Conversely, shared values reduce motivations for opportunistic behaviors and prescribe cooperative activities such as information sharing, which in turn enables healthcare delivery professionals to coordinate better and improve performance (Klein, Rai \& Straub, 2007; Patel, Azadegan \& Ellram, 2013). "Goals serve to focus attention and effort on the desired performance outcome and motivate people to work toward that outcome,” (Field et al., 2014: p. 141). Further, information sharing enhances physicians' performance because it embodies coordination among them and hospital nurses/staff.

We therefore hypothesize:

H3: Information Sharing mediates the relationship between Shared Values and Physicians' Performance irrespective of physician employment with the hospital.

\section{METHODOLOGY}

Primary data was collected to test the hypotheses using survey methods. In this section, we describe the theoretical underpinning of the constructs and measurements items, instrument development, and data collection methods. 


\section{Survey instrument development}

The initial survey items were generated from extant studies which measured the constructs in our study. These items, discussed in the following section, were adapted for the healthcare context through interviews with $\mathrm{PhD}$ qualified researchers well published in the operations and information technology fields, as well as two hospital professionals knowledgeable about the phenomena under study. Next, six healthcare professionals with considerable hospital-based experience were recruited and participated as judges in the Q-sort refine the measures (Churchill, 1979). The study-related expertise of the judges was confirmed by the authors and is validated by their job titles: Chief Ambulatory Medical Information Officer, Service Line Vice President, President of Physician Services and Clinical Integration, Clinical Director and Department Chair, Manager of Care Coordination, and Regional Manager of Physician Relations. Three of the Q-sort judges were Medical Doctors (MDs) and all received previous academic training in clinical areas.

A comprehensive analysis was completed after each Q-sort round to evaluate potential

revisions to ambiguous items. Subsequently, items were deleted, revised, disentangled and/or combined when double-barreled in nature. This process improved construct validity, and highlighted items or combinations thereof that were ambiguous or possessed 'different shades of meaning' (Churchill, 1979). The result was a survey that our expert judges opined was clear and understandable to the extent that “... anyone with hospital knowledge should be able to answer..." Convergent and discriminant validities were evaluated using three methods of interrater reliability; placement ratio, inter-judge raw agreement, and Cohen's Kappa (Moore \& Benbasat, 1991). The Q-sort pilot procedures provided strong support of convergent and discriminant validity all through the process. The final results after the third round were overall 
placement ratio - 96.6\%, raw agreement - 94.0\%, and Kappa score - 93.6\%. Feedback from the judges also supported the relevance of the study. We next describe the theoretical underpinning of the constructs and their operational definitions (measurement items).

\section{Construct items}

Three items measure EMR Use as the extent to which electronic medical records are used to capture clinical documentation such as nursing assessments, problem lists, and advanced directives, as suggested by Ash et al. (2004), AHA (2005), Cutler et al. (2005), Jha et al. (2009). The use of EMR to capture this type of data is prevalent in hospitals and likely to impact patient care (Jha et al., 2009). Information Sharing captures the communication of important information among actors involved in healthcare delivery. Five items measure Information Sharing as the extent to which admitting /attending physicians receive and share patient related information with hospital staff. These items are adapted from IOM (2001), Pagell (2004), Li, Rao, RaguNathan, \& Ragu-Nathan (2005), and Paulraj et al. (2008). The Physicians’ Performance construct conceptualizes the provision of dependable, timely, and appropriate services to patients. Four items measure physicians' performance as the extent to which admitting /attending physicians provide timely, dependable, high quality, and appropriate services to patients. They are adapted from items that measure supplier related reliability from Tan, Kannan, \& Handfield (1998), Vonderembse and Tracey (1999), and Gunesakaran, Patel, \& Tirtiroglu (2001). Four items measure shared values as the extent to which admitting /attending physicians share the hospital's patient care beliefs, objectives, emphasis on collaboration, and interest in improving patient care.

These items are adapted from Nahapiet \& Ghoshal (1998), Wasko \& Faraj (2004), Krause et al. (2007), Carey et al. (2011), and Villena et al. (2011). 
As discussed earlier, studies suggest that roughly $20 \%$ of all physicians are employed by hospitals (Bush, 2012) with the majority of hospitals allowing physicians who are employed as well as those who are not employed by the hospital to treat patients in the hospital (Fink \& Hartzell, 2010). To capture physician employment, each construct was measured using the items mentioned previously in this section, for employed physicians and non-employed physicians, thus creating two sets of items. Increasingly, various forms of alignment are attempted among physicians and hospitals. To clarify any potential ambiguity in the minds of respondents, the survey instrument provided the following definitions. "Employed physicians are those with whom your hospital has a financial contractual relationship. Non-employed physicians are those with whom your hospital does NOT have a financial contractual relationship.” This allowed for analyzing the conceptualized variables and hypothesized relationships using two models; one involving employed physicians (high agency) and one involving non-employed physicians (low agency).

Studies have suggested hospital size and teaching status as key contextual variables in healthcare operations, but the results have been inconclusive with some finding support (Boyer, Gardner, \& Schweikhart, 2012; Goldstein \& Iossifova, 2012) while others have not (Goldstein \& Naor, 2005; McFadden, Henagan, \& Gowan, 2009). We adopted "teaching status" and "bed size” as a control variables given that these hospitals are often hypothesized to employ more innovative technology practices than non-teaching hospitals (Li \& Benton, 2006). Teaching status and bed size were linked to Physicians' Performance in the structural model to assess their control influence in the model. The final items for all constructs are listed in Appendix A. 


\section{Data Collection}

Data were collected from a random sample of American Hospital Association (AHA) acute care facilities using a self-administered internet survey (see Meyer \& Collier, 2001; Li \& Benton, 2006) for other OM/SCM studies using the AHA). The sample frame was populated with email addresses of prospective respondents via a telephone solicitation (e.g. see McFadden et al., 2009). The sample contained of 671 executives from 644 acute care hospitals. Given that 312 executives responded, our response rate is $46.5 \%$ (312/671). Two surveys were deleted due to missing values, leaving 310 responses. We then averaged each item for responses received from multiple raters at the same hospital (eight total) (McFadden et al., 2009). Thus, the final sample contains 302 hospitals in 47 states in the USA. Twenty-one hospitals identified their organizations as "closed systems" meaning that they employ all (100\%) of their physicians. Thus, these cases were removed for analysis of the dataset measuring hospital dealings with nonemployed physicians, resulting in $n=281$ in this sample. Given that we collected data for employed and non-employed physicians, 583 data points $(302+281)$ were used in our analysis. Over 50\% of respondents held the titles of Chief Nursing Officer, VP of Patient Care Services, or Director of Case Management. The remainder primarily includes CEOs, COOs, VPs of Medical Staff Affairs, VPs of Case Management, Directors of Nursing, and Directors of Quality Initiatives. We reviewed job descriptions and received affirmative feedback from our Q-sort judges in confirming the domain knowledge for professional's holding these positions. The sample characteristics for participating hospitals are reported in Table 1.

Insert Table 1 Here 


\section{ANALYSIS AND RESULTS}

Statistical tests were conducted to assess non-response bias. A t-test was used to examine mean differences for bed size. Chi-square tests were performed on hospital type (tertiary, community, or critical access) and for membership in a hospital system. The hospital type of non-respondents was gathered using the internet while data for bed size and system affiliation were received from the AHA. These tests produced no statistically significant differences; thus no evidence of non-response bias (Armstrong \& Overton, 1977).

\section{Measurement model results}

We conducted a confirmatory factor analysis (CFA) using covariance based Structural Equation Modeling (SEM) in AMOS to examine the convergent and divergent validity of constructs. A reflective first order approach was used to model all of the variables. The formulation of reflective constructs was based on literature from healthcare and on literature that provides specification guidelines about formative and reflective constructs. The correlated measurement model results appear in Table 2, showing that all items have a lambda $(\lambda)$ value greater than 0.70 . In addition, all of the items are statistically significant on their hypothesized constructs demonstrating convergent validity (Anderson \& Gerbing, 1988). Two exceptions appear for E3 ( $\lambda=0.58$ for the employed sample, $\lambda=0.59$ for the non-employed sample) and PP1 ( $\lambda=0.66$ for the employed sample, $\lambda=0.64$ for the non-employed sample). Both are statistically significant on their hypothesized constructs and were therefore retained considering their theoretical significance. The measurement model statistics for $X^{2} / \mathrm{df}$, GFI, CFI, NNFI (TLI) and RMSEA appear in Table 2 and are acceptable (Hair, Black, Babin, Anderson \& Tatham, 2006). Finally, all of the variables produce acceptable composite reliabilities (Segars, 1997). 
Insert Table 2 Here

The two models (datasets) were tested for measurement invariance (Hair et al., 2006; Jean, Daekwan, \& Sinkovics, 2012). Cross-validation of the two samples is achieved if the data fits both models well (Hair et al., 2006). Model fit for the employed physician model was $X^{2}=147.25, \mathrm{df}=91, X^{2} / \mathrm{df}=1.62, \mathrm{GFI}=0.94, \mathrm{CFI}=0.98, \mathrm{NNFI}=0.97$, and RMSEA=0.045, and for the non-employed physician sample is $X^{2}=177.11$, d.f. $=91, X^{2} /$ d.f. $=1.95$, GFI $=0.93$, CFI $=0.96$, NNFI $=0.95$, and RMSEA $=0.058$. The results indicate that the data adequately fit both models (Jean et al., 2012). Next, the same CFA model for both groups was tested simultaneously. We tested and compared the model fit of the baseline model (the totally free multiple group model TF) to a model of factor loading equivalence (Hair et al., 2006). The TF baseline model had a model fit of $X^{2}=324.36, \quad \mathrm{df}=182, \quad X^{2} / \mathrm{df}=1.78, \quad \mathrm{GFI}=0.94 ; \quad \mathrm{CFI}=0.97, \quad \mathrm{NNFI}=0.96$, and RMSEA=0.037, which are within acceptable cutoffs (Hair et al., 2006; Jean et al., 2012). In the model of factor loading equivalence, each lambda was constrained across the subsamples. The $X^{2}$ difference between the models is 6.22 with $\mathrm{df}$ of 10 and is not statistically significant $(p=0.80)$. This indicates that the measures are invariant across the subsamples, providing adequate crossvalidation of the employed physician and non-employed physician models (MacCallum, Rosnowski, Mar, \& Reith, 1994; Hair et al., 2006).

A comparison of the average variance extracted (AVE) and variable correlations produced evidence of convergent and discriminant validities (Fornell \& Larcker, 1981). See Tables 3a and 3b. The pairwise $X^{2}$ test was also conducted and provided further evidence of discriminant validity as all of the two-factor correlated models produced lower $X^{2}$ values than their single-factor counterparts, statistically significant at $\mathrm{p}<0.001$ (Segars, 1997). All variable correlations are below the generally accepted cutoff of 0.90 which diminishes collinearity 
concerns (Hair et al., 2006). Finally, variance inflation factor (VIF) and tolerance tests for multicollinearity produce results within acceptable ranges (Hair et al., 2006).

Insert Tables 3a and 3b Here

Common method bias (CMB) was addressed in two ways given that the data was collected from single respondents representing each hospital (Podsakoff, MacKenzie, Lee, \& Podsakoff, 2003). First, from a procedural perspective, following Podsakoff et al., (2003) the questionnaire items measuring the predictor and criterion variables were positioned in different sections of the instrument to decrease the likelihood of CMB by making it hard for respondents to link the targeted measures. Second, in order to test for CMB after data collection, Harmon's single factor test was conducted and a single dominant factor did not emerge (Shafiq, Klassen, \& Johnson, 2014). Instead four factors with Eigen values greater than one emerged for both data sets (employed and non-employed physicians) providing no evidence of CMB.

\section{Structural model results}

The results from the structural model appear in Table 4, and Figures 2 and 3. Direct and indirect effects for mediation testing were conducted in AMOS by estimating bootstrap standard errors using 2,000 sample replications (Fox, 1980). Support is provided for H1, Information Sharing fully mediates the relationship between EMR Use and Physicians' Performance for independent (non-employed) physicians. The analysis of the non-employed physician data set reveals that EMR use has a direct effect on Information Sharing (coefficient=0.22, $p<0.01$ ), Information Sharing has a direct effect in Physicians’ Performance (coefficient=0.45, $p<0.01$ ), and EMR use has an indirect effect on Physicians' Performance (coefficient=0.09, $p=0.06$ ). In the employed physician data set, EMR use does not affect Information Sharing (coefficient=0.03, $p=0.49)$. 
Insert Table 4, and Figures 2 and 3Here

Support is provided for H2, Shared Values fully mediates the relationship between EMR Use and Physicians' Performance for employed physicians. The analysis of the employed physician data set reveals that EMR use has a direct effect on Shared Values (coefficient $=0.15$, $p<0.05$ ), Shared Values has a direct effect in Physicians' Performance (coefficient $=0.43$, $p<0.01$ ), and EMR use has an indirect effect on Physicians' Performance (coefficient $=0.10$, $p<0.05)$. In the non-employed physician data set, EMR use does not affect Shared Values (coefficient=-0.01, $p=0.90$ ).

Finally, support is provided for H3, Information Sharing partially mediates the relationship between Shared Values and Physicians' Performance irrespective of physician employment with the hospital. Here both data sets provide the same statistical interpretations. Shared Values has a direct effect on Information Sharing in both groups (coefficient $=0.64$, $p<0.01$ for employed physicians, and coefficient $=0.50, p<0.01$ for non-employed physicians). Shared Values also has a direct effect in Physicians' Performance in both groups (coefficient=0.43, $p<0.01$ for employed physicians and coefficient=0.38, $p<0.01$ for nonemployed physicians). Finally, Shared Values has an indirect effect on Physicians’ Performance (coefficient=0.20, $p<0.01$ for employed physicians and coefficient=0.23, $p<0.01$ for nonemployed physicians).

We also note that Teaching Status and Bed Size, which were included in the model as a control variables and were not statistically significant. Therefore our results hold irrespective of the extent of teaching in the hospital or hospital size. 


\section{DISCUSSION}

Healthcare delivery processes in hospitals embody high levels of complexity for a number of reasons - namely, interdependent and dispersed processes that require ongoing coordination, and specialized, varied and often contractually independent people executing these processes. It is not surprising perhaps, that benefits from use of EMR to record clinical information are not readily apparent in such an environment (e.g. Queenan et al., 2011; Nembhard et al., 2009). This study identifies pathways from EMR use by healthcare delivery professionals in a hospital, to physicians’ performance. To address process inter-dependency, we examine how EMR use can lead to improved physicians’ performance through information sharing among healthcare delivery professionals. To address the independence of healthcare delivery actors, we suggest shared values between the hospital and physician as a means to enhance information sharing. Recognizing the emerging importance of and discussion around physician employment (Andrabi, 2012), we identify its impacts on the relationship between EMR use, and information sharing and shared values. We make the following contributions.

\section{Scholarly contributions}

The paper makes three important scholarly contributions. First, it opens the black box linking EMR use and physicians’ performance by carefully considering the contextual specifics of healthcare delivery. We explain the link between EMR use and physicians' performance by conceptualizing and validating a mediating role for coordination in the form of information sharing, and for shared values. Our explanation is a potential solution to the inherent problems of fragmentation and interdependencies in healthcare delivery processes. Previous research has highlighted the need for, and absence of, coordination among healthcare professionals as an important issue (Gittel \& Weiss, 2004), and has addressed the beneficial impacts of coordination 
among independent organizations in healthcare supply chains (e.g. Shah et al., 2008). However it does not explain the calculus of coordination among individual healthcare delivery professionals involved in healthcare delivery processes, which has been conceptualized as a critical link in the causal chain for satisfactory healthcare outcomes (Gittel and Weiss, 2004; Fredendall et al., 2009). This paper reveals the roles of information sharing and shared values in appropriating physicians' performance from EMR use. The absence of the direct relationship between EMR use and physicians' performance in our results further validates the centrality of the coordination logic.

We provide a possible explanation for the ambiguous and contradicting outcomes from EMR use. Current studies examining the consequences of healthcare IT implementation provide interesting contrast. Some studies (e.g., Devaraj et al., 2013, Angst, Deveraj, Queenan, \& Greenwood, 2011), focusing on process efficiency impacts of healthcare IT, suggest that its use facilitates more efficient operations and quicker patient flows, leading to improved hospital performance. Others, focusing on use of healthcare IT (e.g., Queenan et al., 2011) find that use (e.g. of computerized order entry systems) does not always lead to patient satisfaction and that overall general IT infrastructure can actually substitute for such systems. We qualify these findings by showing that while the adoption of EMR by hospitals and its use by healthcare delivery professional are important, these actions alone may not improve outcomes such as physicians' performance. A key role of electronic clinical documentation is to facilitate information sharing and shared values between healthcare delivery professionals and that superior physicians' performance accrues from such coordination. We thus explain when performance benefits from EMR are expected to occur. In doing so, we provide a pathway from health IT (i.e., EMR use) to process (i.e., information sharing and shared values), to outcomes 
(i.e., physicians' performance). We note that existing studies focus mostly on the health IT outcome link in a somewhat black-box fashion, providing an opportunity to carefully consider the contextual particulars of healthcare delivery processes in explaining this link. (e.g. BenAssuli \& Leshno, 2013; Smith et al., 2013).

Second, our study addresses some of the current curiosity regarding physician employment in healthcare delivery, using an agency lens. We note that physicians may not share the same goals as that of the hospital. For instance, while bettering patient service is an important goal for a hospital, physicians may find it more important to minimize the time to see each patient when working under fee-for-service (volume) reimbursements arrangements from insurance companies. Indeed the hospital has been described as a "foster parent who has adopted fully formed adults committed to different religions," implying that there could be a lack of unity of purpose between the physician and the hospital (Ramanujam \& Rosseau, 2006; Nembhard et al., 2009: p. 30).

We suggest that a "shared vision" between the physician and hospital, expected to be low, is critical to information sharing. While much of the discourse regarding the agency relationship between hospitals and physicians has been conceptual in nature and is reasonably dated (Dranove \& White, 1987; Dranove \& White, 1989; McLean, 1989), more recent empirical studies have provided inconclusive results when testing the role of physician employment in influencing the efficiency of healthcare providers (Ciliberto \& Dranove, 2006; Cueller \& Gertler, 2006). Our results show that EMR use boosts information sharing when physicians are independent of the hospital and increases shared values when they are employed by the hospital. Taken together, these results indicate that when the agency aspect is addressed through employment, EMR use provides a means to enhance the social aspects of the relationship 
between the physician and the hospital by strengthening shared values between them. On the other hand, for non-employed independent physicians, EMR use provides an information access platform to improve their work practices regarding information sharing. Therefore, we suggest that agency influences the way in which EMR use is appropriated by employed and nonemployed, independent physicians. We submit this to be a finding of theoretical interest and novelty given that to the authors' knowledge this is one of the earliest papers to examine physician employment and EMR use.

Third, based on an important context-specific aspect of healthcare delivery, namely that healthcare processes are performed by professionals (i.e., physicians) who may not strongly identify with the focal organization that delivers these processes (Schneller \& Smeltzer, 2006; Boyer \& Pronovost, 2010), we suggest shared values as a tool for enhancing coordination. Shared values has been examined in the traditional product supply chain literature as an enabler of benefits such as supply chain efficiency, cost reduction and product/process improvements through more effective institutional interactions between supply chain partners (Krause et al., 2007; Carey et al., 2011). The positive relationship between shared values and both information sharing and physicians' performance draws attention to its relevance in interactions among individuals in a service delivery context that requires coordination. We find that shared values is an important motivator of information sharing and physicians' performance regardless of physician employment status, extending the theoretical ambit of shared values in the operations management literature (e.g., Krause et al., 2007 and others).

An additional methodological contribution of our study exists in the data collected and analyzed. Given the requirement for testing the effects of the observable phenomena of information sharing and shared values addressed in our research questions, in employed as well 
as non-employed physicians, it was necessary to collect primary data. This procedure produced two datasets for a total of 583 data points, requiring the testing of two discrete models for invariance. The results of our analysis produced evidence of measurement invariance between the models, while pointing to differences implied by the hypotheses. Therefore, we are able to show that the measurement of EMR use, information sharing, shared values, and physicians' performance are not statistically different between the employed and non-employed physician datasets. However, key relationships among these variables change based on physician employment, as hypothesized. This approach can be applied to other operations and supply chain management and information systems research contexts such as buyer and supplier behavior where it may be useful to test relationships among constructs of interest measuring the same phenomena for two different values of a particular parameter.

Finally, we propose and validate relationships that future studies examining contexts where independent actors are called upon to perform inter-dependent tasks to achieve a common objective, can draw on. Such a situation is becoming increasingly common in a number of operational domains such as in healthcare, legal, financial, and reverse supply chains where service science engineering and management can be applied to improve process oriented IT deployment intended to facilitate collaboration among dispersed entities in pursuit of value cocreation (Schmenner et al., 2009).

\section{Managerial contributions}

Healthcare delivery processes are complex and information intensive, and have been traditionally hampered by a lack of coordination (Buell, 2013). It is probable that these challenges impede the translation of EMR use into improved performance, and have consequently played a role in the slow adoption of IT to improve provider performance (Ilie et 
al., 2009). However, EMR adoption has started and will likely continue to increase so long as federal incentives encourage IT use as a critical means of improving healthcare delivery (Smith et al., 2013).

This study provides healthcare practitioners with an improved sense of how to effectively manage the EMR use translation process into improved performance. It demonstrates that merely increasing the extent of use of EMR by physicians and hospital staff alone is insufficient. EMR use is not directly related to improved physicians' performance. Rather, EMR use can be effective when implemented along with effective information sharing practices whereby physicians and the hospital staff communicate about changing patient needs, keep each other informed, and document and provide access to treatment plans. These practices represent a pathway to improved physician performance. Healthcare providers will benefit from knowing that EMR use delivers benefits when, in addition to using EMR for routine clinical documentation, they also engage in reciprocal information sharing regarding the patient's needs and treatment plan.

Next, we show that a physician-hospital relationship that is high on shared values can also translate EMR use into better physician performance and improve information sharing. We provide practical guidance for tackling the issues of how to extract value from employed physicians via EMR use, and also offer direction to address information asymmetry between physicians and hospital staff. It is interesting to consider trade studies (Andrabi, 2012) and the authors' own field experience with physicians and hospital staff, which point to a lack of precisely those qualities embodied by strong shared values, in many physician-hospital relationships. 
For policy makers and executives, our study sheds light on the timely topic of physician employment. For executives contemplating the consequences of employing physicians, our results indicate that it is possible to enhance shared values with physicians through implementing EMR and employing physicians. This suggests that the overarching aim of physician employment to align the behavior of physicians with the interests of the hospital may indeed be effective in influencing physicians' performance, when in conjunction, EMR is also used by healthcare delivery actors to boost shared values.

\section{LIMITATIONS AND FUTURE RESEARCH}

We acknowledge several limitations and highlight counter measures where possible in our study. To begin, while it was necessary to achieve our aim of studying employed and nonemployed physicians, our study suffers from the typical shortcomings of survey research. Data were collected from a single respondent from each hospital, and thus while we tested for and found no evidence of common method bias, it may not be appropriate to completely rule it out. It is however worth noting that the key respondent for our survey was carefully selected based on job description reviews and input from expert judges provided during instrument development. For these reasons, it is reasonable to expect that the respondents in our study are subject matter experts and appropriate for this study (Craighead, Ketchen, \& Dunn, 2011). Also, with regard to employment and incentive alignment, a myriad of organizational structures and arrangements exist among hospitals and physicians (e.g., Managed Service Organizations (MSOs), Professional Services Agreements (PSAs), Accountable Care Organizations (ACOs), among other structures) and these warrant future investigation. A more finely grained examination of these financial arrangements may further illuminate and qualify the results presented herein, particularly those involving shared values, information sharing, and physicians' performance that 
were not shown to differ based on employment status. Given the complex nature of the issues we studied, namely, use of EMR by healthcare delivery providers in the hospital and physicianhospital alignment, qualitative research designs that combine interviews and observations could reveal rich insights about how EMR systems are actually used, how that depends on various forms of physician-hospital alignment, and what the associated operational outcomes are, further qualifying and triangulating the results reported here.

Our study produced high-level findings which hold at the hospital level while controlling for teaching status and bed size, common differentiating factors among hospitals. The use of these control variables to some extent supports the generalizability of our findings. That said, future research may seek to address technology use at a more granular level, in individual departments or units within hospitals. This would be useful given that different services or departments in the hospital may use technology differently (similar to Devaraj et al. 2013). Further, the use of technology may have different impacts and pathways to those impacts, when used in specialized clinical contexts, departments, or when different types of information are sought (Wilson, Dobrzykowski \& Cazier, 2008; Dobrzykowski \& Tarafdar, 2015). Our study also does not take into account potential antecedents of EMR use such as physician participation in system design, training, and other supportive mechanisms employed by hospitals (similar to Queenan et al., 2011). These variables could provide a window into the heterogeneity that exists in seemingly isomorphic hospital operational practices (Bhakoo \& Choi, 2013). Finally, future studies are warranted to explore the problems of coordination and agency highlighted in this paper in other important operational phenomena such as process improvement, and integration, and with an eye toward desirable outcomes such as efficiency, safety, quality, and patient satisfaction. 


\section{CONCLUSION}

The promise of information technology applied to healthcare delivery processes, though

partly fulfilled through decreased data/process error and more streamlined operations for hospital, continues to remain elusive. In particular, reports on positive impacts of EMR use on clinical outcomes are far from conclusive. This paper shows that improved physicians' performance from EMR use occurs via a fully mediated impact of information sharing enabled coordination between physicians, nurses and hospital staff, aided by shared values between the hospital and physicians, and influenced by physician employment. In doing so, it reveals the hitherto relatively un-examined role of these important factors in translating EMR use to into physicians’ performance.

\section{Appendix A. Survey Instrument (Items)}

Likert scales items: 1-strongly disagree, 2-disagree, 3-nuetral, 4-agree, 5-strongly agree.

N/A was also offered as a response choice.

Respondents were asked to opine for each item with regard to their hospital's dealings with employed physicians and non-employed physicians. Definitions were provided for Employed physicians as those with whom your hospital has a financial contractual relationship and non-employed physicians as those with whom your hospital does NOT have a financial contractual relationship.

\section{EMR use}

We use EMR to capture:

E1: nursing assessments.

E2: problem lists.

E3: advanced directives.

\section{Information Sharing}

Our admitting/attending physicians:

IS1: receive information from us about changing patient needs. (deleted)

IS2: share patient information with us.

IS3: keep us informed about issues that affect care delivery.

IS4: share information with us that helps establish treatment plans.

IS5: work with our staff to keep each other informed about changes that may affect care delivery.

\section{Shared Values}

Our admitting/attending physicians share our:

SV1: patient care beliefs.

SV2: patient care objectives.

SV3: emphasis on collaboration in patient care.

\section{Physicians' Performance}

Our admitting/attending physicians provide:

PP1: timely services (e.g., rounding) to patients.

PP2: dependable services to patients.

PP3: high quality services to patients.

PP4: an appropriate level of services to patients. 
Control: Teaching status

Please check all that apply. $\square$ Major Teaching Hospital; $\square$ Minor Teaching Hospital; or $\square$ Non-teaching Hospital

Control: Bed size

Please estimate the number of staffed beds in your hospital. $\square 1$ - 49; $\square 50$ - 99; $\square 100$ - 199; $\square 200$ - 399;

$\square$ More than 400

\section{References}

Advisory Board Company. (2014). Dallas hospital leader: 'We are deeply sorry' for our mistakes: Ebola patient was not isolated for two days, records show. Retrieved from http://www.advisory.com/daily-briefing/2014/10/16/dallas-hospital-leader-we-are-deeply-sorryfor-our-mistakes on October 18, 2014.

Agarwal, R., Gao, G., DesRoches, C., \& Jha, A.K. (2010). The digital transformation of healthcare: Current status and the road ahead. Information Systems Research, 21(4), 796-809.

Agency for Healthcare Research and Quality (AHRQ). (2013). Findings and Lessons From the Enabling Patient- Centered Care Through Health IT Grant Initiative. (Prepared by Westat Under Contract No. HHSA 290200900023I.) AHRQ Publication No. 13-0011- EF. Rockville, MD: Agency for Healthcare Research and Quality January 1-29.

American College of Healthcare Executives (ACHE). (2013). Top issues confronting hospitals: 2013. Retrieved on June 10, 2014 at http://www.ache.org/pubs/research/ceoissues.cfm.

American Hospital Association (AHA), (2005). Forward momentum: hospital use of information technology. Chicago: American Hospital Association.

Anderson, J.C., \& Gerbing, D.W. (1988). Structural equation modeling in practice: a review and recommended two-step approach. Psychological Bulletin, 103(3), 411-423.

Andrabi, I. (2012). Furthering our missions: physician strategy as the foundation to improving community health. Becker's Hospital Review, March 30, 2012.

Angst, C.M., Deveraj, S., Queenan, C.C., \& Greenwood, B. (2011). Performance Effects Related to the Sequence of Integration of Healthcare Technologies. Production Operations Management, 20(3), May-June, 319-333.

Armstrong, J.S., \& Overton, T.S. (1977). Estimating non-response bias in mail surveys. Journal of Marketing Research 24, 396-402.

Ash, J. S., Gorman, P. N., Seshadri, V., \& Hersh, W. R. (2004). Computerized physician order entry in U.S. hospitals: results from a 2002 survey. Journal of American Medical Informatics Association, 11, 95-99.

Ben-Assuli, O. \& Leshno, M. (2013). Using Electronic Medical Records in Admission Decisions: A Cost Effectiveness Analysis. Decision Sciences, 44(3), 463-481.

Bhakoo, V., \& Choi, T. (2013). The iron cage exposed: Institutional pressures and heterogeneity across the healthcare supply chain. Journal of Operations Management, 31(6), 432-449.

Boyer, K., \& Pronovost, P. (2010). What medicine can teach operations: What operations can teach medicine. Journal of Operations Management, 28(5), 367-371.

Boyer, K.K., Gardner, J.W., \& Schweikhart, S. (2012). Process quality improvement: An examination of general vs. outcome-specific climate and practices in hospitals. Journal of Operations Management, 30, 325-339.

Buell, J. (2013). Health Information Exchange: Achieving coordinated care. Healthcare Executive, 28(5), 10-18.

Burton-Jones, A., \& Gallivan, M. (2007). Towards a Fuller Understanding of System Usage in Organizations: A Multilevel Perspective. MIS Quarterly, 31(4) 657-679.

Bush, H. (2012). Hospital statistics chart rise in physician employment. Hospital \& Health Networks Daily, January 6, 2012.

Carey, S., Lawson, B., \& Krause, D.R. (2011). Social capital configuration, legal bonds and performance in buyer-supplier relationships. Journal of Operations Management, 29, 277-288. 
Chang, L. (2011). The effect of health payment reforms on cost containment in Taiwan hospitals: The Agency Theory perspective. Journal of Healthcare Finance, 38(1), 11-31.

Churchill Jr., G.A. (1979). A paradigm for developing better measures of marketing constructs. Journal of Marketing Research, 16 (February), 64-73.

Ciliberto, F., \& Dranove, D. (2006). The effect of physician-hospital affiliations on hospital prices in California. Journal of Health Economics, 25, 29-38.

Coiera, E. (2000). When conversation is better than computation. Journal of the American Medical Informatics Association, 7(3), 277-286.

Craighead, C.W., Ketchen, D.J., Dunn, K.S., \& Hult, G. (2011). Addressing common method variance: guidelines for survey research on information technology, operations, and supply chain management. IEEE Transactions on Engineering Management, 58, 578-588.

Cuellar, A.E., \& Gertler, P.J. (2006). Strategic integration of hospitals and physicians. Journal of Health Economics, 25, 1-28.

Cutler, D. M., Feldman, N. E., \& Horowitz, J. R. (2005). U.S. adoption of computerized physician order entry systems. Health Affairs, 24, 1654-1663.

DeSanctis, G., \& Poole, M. S. (1994). Capturing the Complexity in Advanced Technology Use: Adaptive Structuration Theory. Organization Science, 5(2), pp. 121-147.

Devaraj, S., \& Kohli, R. (2003). Performance Impacts of Information Technology: Is Actual Usage the Missing Link? Management Science, 49(3), 273-289.

Devaraj, S., \& Kohli, R. (2000). Information technology payoff in the healthcare industry: A longitudinal study. Journal of Management Information Systems, 16(4), 41-67.

Devaraj, S., Ow, T. T., \& Kohli, R. (2013). Examining the impact of information technology and patient flow on healthcare performance: A Theory of Swift and Even Flow (TSEF) perspective. Journal of Operations Management, 31(4), 181-192.

Dobrzykowski, D., \& Tarafdar, M. (2015). Understanding information exchange in healthcare operations: Evidence from hospitals and patients. Journal of Operations Management, 36, 201-214.

Dobrzykowski, D.D., Callaway, S.K., \& Vonderembse, M.A. (2015). Examining pathways from innovation orientation to patient satisfaction: a relational view of healthcare delivery. Decision Sciences, 46(5), 863-899.

Dobrzykowski, D. (2012). Examining heterogeneous patterns of Electronic Health Records Use: A contingency perspective and assessment. International Journal of Healthcare Information Systems and Informatics, 7(2), 1-16.

Dranove, D., \& White, W.D. (1989). Agency Theory: new insights into the heal care industry. The Journal of Medical Practice Management, 4(3), 165-169.

Dranove, D., \& White, W.D. (1987). Agency and the organization of healthcare delivery. Inquiry, 24 (Winter), 405-415.

Dyer, J.H., \& Singh, H. (1998). The relational view: cooperative strategy and sources of interorganizational competitive advantage. Academy of Management Review, 23(4), 660-679.

Eisenhardt, K. M. (1989). Agency Theory: An Assessment and Review. Academy of Management Review, 14(1), 57-74.

Field, J.M., Heineke, J., Langabeer, J.R., \& DelliFraine, J.L. (2014). Building the Case for Quality Improvement in the Health Care Industry: A Focus on Goals and Training. Quality Management in Health Care, 23(3), 138-154.

Fink, J.N., \& Hartzell, S.T. (2010). From acquisition to integration. Healthcare Financial Management, 64(10), 90-98.

Forgione, D.A., Vermeer, T.E., Surysekar, K., Wrieden, J.A. \& Plante, C.C. (2005). DRGs, costs and quality of care: An Agency Theory perspective. Financial Accountability \& Management, 21(3), 291-308.

Ford, E., \& Scanlon, D. (2007). Promise and problems with supply chain management approaches to healthcare purchasing. Healthcare Management Review, 32(3), 192-202. 
Fornell, C., \& Larcker, D. (1981). Evaluating structural equations models with unobservable variables and measurement error. Journal of Marketing Research, 18(3), 39-50.

Fox, J. (1980). Effect analysis in structural equation models. Sociological Methods and Research, 9, 3-28.

Fredendall, L. D., Craig, J. B., Fowler, P. J., \& Damali, U. (2009). Barriers to swift, even flow in the internal supply chain of perioperative surgical services department: A case study. Decision Sciences, 40(2), 327-349.

Galbraith, J. (1973). Designing Complex Organizations. Addison-Wesley, Reading, MA.

Gittell, J.H., Fairchild, K.M., Bierbaum, B., Head, W., Jackson, R., Kelly, M., Laskin, R., Lipson, S., Siliski, J., Thornhill, T., \& Zuckerman, J. (2000). Impact of Relational Coordination on Quality of Care, Postoperative Pain and Functioning, and Length of Stay: A Nine-Hospital Study of Surgical Patients. Medical Care, 38(8), 807-819.

Gittell, J. H., \& Weiss, L. (2004). Coordination Networks Within and Across Organizations: A Multi-level Framework. Journal of Management Studies, 41(1), 127-153.

Gittell, J. H. (2002). Coordinating mechanisms in care provider groups: Relational coordination as a mediator and input uncertainty as a moderator of performance effects. Management Science, 48(11), 1408-1426.

Goh, J.M., Gao, G., \& Agarwal, R. (2011). Evolving Work Routines: Adaptive Routinization of Information Technology in Healthcare. Information Systems Research, 22(3), 565-585.

Goldstein, S.M., \& Iossifova, A.R. (2012). Ten years after: Interference of hospital slack in process performance benefits of quality practices. Journal of Operations Management, 30, 44-54.

Goldstein, S.M., \& Naor, M. (2005). Linking publicness to operations management practices: a study of quality management practices in hospitals. Journal of Operations Management, 23, 209-228.

Goodale, J.C., Kuratko, D.F., \& Hornsby, J.S. (2008). Influence factors for operational control and compensation in professional service firms. Journal of Operations Management, 26, 669-688.

Gordon, R., Guest, D., Kazzaz, Z., \& Snyder, K. (2011). Physician/hospital alignment: Employment agreements in the reform era. Deloitte Development, LLC., 1-16.

Government Accountability Office (GAO) (2005). $21^{\text {st }}$ century challenges: Reexamining the base of the federal (February).

Gunasekaran, A., Patel, C., \& Tirtiroglu, E. (2001). Performance measures and metrics in a supply chain environment. International Journal of Operations and Production Management, 21(1-2), 71-87.

Green, L. (2012). OM Forum-The Vital Role of Operations Analysis in Improving Healthcare Delivery. Manufacturing \& Service Operations Management, 14(4), 488-494.

Hair, J., Black, W., Babin, B., Anderson, R., \& Tatham, R. (2006). Multivariate Data Analysis. Pearson Prentice Hall, Upper Saddle River, NJ.

Hsu, I-C. \& Sabherwal, R. (2012). Relationship between Intellectual Capital and Knowledge Management: An Empirical Investigation. Decision Sciences, 43(3), 489-524.

Huang, M-H. \& Wang, E.T.G. (2013). Marketing Is from Mars, IT Is from Venus: Aligning the World views for Firm Performance. Decision Sciences, 44(1), 87-125.

Ilie, V., Van Slyke, C., Parikh, M., \& Courtney, J. (2009). Paper versus electronic medical records: the effects of access on physicians. Decision Sciences, 40(2), 213-242.

Inkpen, A.C., \& Tsang, E.W.K. (2005). Social capital, networks, and knowledge transfer. Academy of Management Review, 30(1), 146-165.

Institute of Medicine (IOM). (2001). Crossing the quality chasm: A new health system for the $21^{\text {st }}$ century. Washington, DC: National Academy Press.

Jean, R-J, Daekwan, J., \& Sinkovics, R.R. (2012). Drivers and performance outcomes of supplier innovation generation in customer -supplier relationships: The role of power dependence. Decision Sciences, 43(6), 1003-1038.

Jha, A. K., DesRoches, C. M., Campbell, E. G., Donelan, K., Rao, S. R., Ferris, T. G., et al. (2009). Use of Electronic Health Records in U.S. Hospitals. The New England Journal of Medicine, 360(16), 1628-1638. 
Karsten, H. (2003). Constructing Interdependencies with Collaborative Information Technology, Computer Supported Cooperative Work, 12, 437-464.

Kenagy, J., Berwick, D., \& Shore, M. (1999). Service quality in health care. Journal of the American Medical Association, 281, 661-665

Klein, R., Rai, A. \& Straub, D.W. (2007). Competivitive and cooperative positioning in supply chain logistics relationships. Decision Sciences, 38(4), 611-645.

Krause, D.R., Handfield, R.B., \& Tyler, B.B. (2007). The relationships between supplier development, commitment, social capital accumulation and performance improvement. Journal of Operations Management, 25(2), 528-545.

Lamb, R., \& Kling, R. (2003). Reconceptualizing Users as Social Actors in Information Systems Research. MIS Quarterly, 27(2), 197-235.

Lahiri, A., \& Seidmann, A. (2012). Information hang-overs in Healthcare Service Systems. Manufacturing \& Service Operations Management, 14(4), 634-653.

Lawrence, P., \& Lorsch. (1976). Differentiation and integration in complex organizations. Administrative science Quarterly, 1-47.

Leape, L., \& Berwick, L. (2005). Five years after to err is human. JAMA: The journal of the American Medical Association, 293(19), 2384-2390.

Li, S., Rao, S., Ragu-Nathan, T., \& Ragu-Nathan, B. (2005). Development and validation f a measurement instrument for studying supply chain management practices. Journal of Operations Management, 23, 618-641.

Li, L., \& Benton, W.C. (2006). Hospital technology and nurse staffing management decisions. Journal of Operations Management, 24, 676-691.

MacCallum, R.M., Rosnowski, M., Mar, C., \& Reith. (1994). Alternative strategies for cross-validation of covariance structure models. Multivariate Behavioral Research, 29, 1-32.

Malone, T.W., \& Crowston, K. (1994). The interdisciplinary study of coordination. ACM Computing Surveys (CSUR), 26(1), 87-119.

Markus, M., \& Tanis, C. (2000). Enterprise Systems Experience--From Adoption to Success. Cincinnati, OH: Pinnaflex Educational Resources, Inc.

Massetti, B., \& Zmud, R. W. (1996). Measuring the Extent of EDI Usage in Complex Organizations: Strategies and Illustrative Examples. MIS Quarterly, 20(3), 331-345.

McCullough, J. S., Casey, M., Moscovice, I., \& Prasad, S. (2010). The effect of health information technology on quality in US hospitals. Health Affairs, 29(4), 647-654.

McFadden, K.L., Henagan, S.C., \& Gowen, C.R., III. (2009). The patient safety chain: Transformational leadership's effect on patient safety culture, initiatives, and outcomes. Journal of Operations Management, 27, 390-404.

McLean, RA. (1989). Agency costs and complex contracts in health care organizations. Health Care Management Review, 14(1), 65-71.

Meyer, S.M., \& Collier, D.A. (2001). An empirical test of the causal relationships in the Baldrige Health Care Pilot Criteria. Journal of Operations Management, 19, 403-425.

Moore, G.C., \& Benbasat, I. (1991). Development of an instrument to measure the perceptions of adopting an information technology innovation. Information Systems Research, 2(3), 192-222.

Nahapiet, J., \& Ghoshal, S. (1998). Social capital, intellectual capital, and the organizational advantage. Academy of Management Review, 23(2), 242-266.

Nembhard, I.M., Alexander, J.T.H., \& Ramanujam, R. (2009). Why does the quality of health care continue to lag? Insights from management research. Academy of Management Perspectives, 23(1), 24-42.

Orlikowski, W. J. (1996). Improvising Organizational Transformation Over Time: A Situated Change Perspective. Information Systems Research, (7), 63-92.

Pagell, M. (2004). Understanding the factors that enable and inhibit the integration of operations, purchasing and logistics. Journal of Operations Management, 22, 459-487. 
Paulraj, A., Lado, A., \& Injazz, C. (2008). Inter-organizational communication as a relational competency: Antecedents and performance outcomes in collaborative buyer-supplier relationships. Journal of Operations Management, 26, 45-64.

Patel, P.C., Azadegan, A. \& Ellram, L.M. (2013). The Effects of Strategic and Structural Supply Chain Orientation on Operational and Customer-Focused Performance. Decision Sciences, 44(4), 713753.

Podsakoff, P.M., MacKenzi, S.B., Lee, J.Y., \& Podsakoff, N.P. (2003). Common method biases in behavioral research: A critical review of the literature and recommended remedies. Journal of Applied Psychology, 88(5), 879-903.

Poissant, L., Pereira, J., Tamblyn, R., \& Kawasumi, Y. (2005). The impact of electronic health records on time efficiency of physicians and nurses: A systematic review. Journal of American Medical Informatics Association, 12(5), 505-516.

Prahalad, C.K., \& Ramaswamy, V. (2004). Co-creation experiences: the next practice in value creation, Journal of Interactive Marketing, 18(3), 5-14.

Queenan, C.C., Angst, C.M., \& Devaraj, S. (2011). Doctors' orders-If they're electronic, do they improve patient satisfaction? A complements/substitutes perspective. Journal of Operations Management, 29(7), 639-649.

Ramanujam, R., \& Rousseau, D.M. (2006). The challenges are organizational not just clinical. Journal of Organizational Behavior, 27(7), 811-827.

Reddy, S.T., Iwaz, J.A., Didwania, A.K., O’Leary, K.J., Anderson, R.A., Humphrey, H.J., Farnan, J.M., Wayne, D.B., \& Arora, V.M. (2012). Participation in unprofessional behaviors among hospitalists: A multicenter study. Journal of Hospital Medicine, 7(7), 543-550.

Segars, A. (1997). Assessing the unidimensionality of measurement: a paradigm and illustration within the context of information systems research. Omega: International Journal of Management Science, 25(1), 107-121.

Schmenner, R.W., Van Wassenhove, L., Ketokivi, M., Heyl, J., \& Lusch, R.F. (2009). Too much theory, not enough understanding. Journal of Operations Management, 27, 339-343.

Schneller, E.S., \& Epstein, K.R. (2006). The hospitalist movement in the United States: agency and common agency issues. Health Care Management Review, 31(4), 308-316.

Schneller, E.S., \& Smeltzer, L.R. (2006). Strategic management of the health care supply chain. San Francisco, CA: Jossey-Bass.

Schramko, T.D. (2007). The Characteristics of an Effective Physician-Hospital Working Relationship: An Exploratory Study. Health Care Annals, 15, 91-105.

Scott, J. T., Rundall, T. G., Vogt, T. M., \& Hsu, J. (2005). Kaiser Permanente's experience of implementing an electronic medical record: a qualitative study. British Medical Journal, 331 (November), 1313-1316.

Shafiq, A., Klassen, R.D., \& Johnson, P.F. (2014). Socially responsible practices: An exploratory study on scale development using stakeholder theory. Decision Sciences, 45(4), 683-716.

Shah, R., Goldstein, S., Unger, B., Henry, T., 2008. Explaining anomolous high performance in a health care supply chain. Decision Sciences, 39(4), 759-789.

Simatupang, T. M., Sandroto, I. V., \& Lubis, S. H. (2004). Supply chain coordination in a fashion firm. Supply Chain Management: An International Journal, 9(3), 256-268.

Sinha, K. \& Kohnke, E. (2009). Health care supply chain design: toward linking the development and delivery of care globally. Decision Sciences, 40(2), 197-212.

Smelcer, J.B., Jacobs-Miller, H., \& Kantrovich, L. (2009). Usability of electronic medical records. Journal of Usability Studies, 4(2), 70-84.

Smith, A.L., Bradley, R.V., Bichescu, B.C., \& Tremblay, M.C. (2013). IT Governance Characteristics, Electronic Medical Records Sophistication, and Financial Performance in U.S. Hospitals: An Empirical Investigation. Decision Sciences, 44(3), 483-516.

Sobun, C. (2002). How to Use Information Systems to the Fullest. In: IT Health Care Strategist. Aspen Publishers Inc. 5. 
Speier, C., Whipple, J.M., Closs, D.J., \& Voss, M.D. (2011). Global supply chain design considerations: Mitigating product safety and security risks. Journal of Operations Management, 29, 721-736.

Tan, K., Kannan V., \& Handfield R. (1998). Supply chain management: supplier performance and firm performance. International Journal of Purchasing and Materials Management, 34(3), 2-9.

Thompson, J. (1967). Organizations in Action. New York: McGraw-Hill.

Trybou, J., Gemmel, P., \& Annemans, L. (2011). The ties that bind: An integrative framework of physician-hospital alignment. BMC Health Services Research, 11(36), 1-5.

Tucker, A. (2004). The impact of operational failures on hospital nurses and their patients. Journal of Operations Management, 22, 151-169.

Vargo, S.L., \& Lusch, R.F. (2004). Evolving to a new dominant logic for marketing. Journal of Marketing, 68 (January), 1-17.

Villena, V. H., Revilla, E., \& Choi, T.Y. (2011). The dark side of buyer-supplier relationships: A social capital perspective. Journal of Operations Management, 29(6), 561-576.

Vonderembse, M.A., \& Tracey, M. (1999). The impact of supplier selection criteria and supplier involvement on manufacturing performance. Journal of Supply Chain Management, 35(3), 33-39.

Wasko, M.M., \& Faraj, S. (2005). Why should I share? Examining social capital and knowledge contribution in electronic networks of practice. MIS quarterly, 35-57.

Wilson, E. V., Dobrzykowski, D. D., \& Cazier, J. A. (2008). The influence of media trust and internet trust on privacy-risking uses of e-health. International Journal of Information Security and Privacy, 2(3), July-September, 84-97. 
Table 1: Sample characteristics (full sample, $n=302$ hospitals).

\begin{tabular}{|c|c|c|c|}
\hline Characteristics & Respondents & Characteristics & Respondents \\
\hline Hospital type & & Size - number of beds & \\
\hline Tertiary care center & $67(22 \%)$ & $<49$ & $40(13 \%)$ \\
\hline Community hospital & $189(63 \%)$ & $50-99$ & $59(20 \%)$ \\
\hline Critical access hospital & $39(13 \%)$ & 100-199 & $64(21 \%)$ \\
\hline \multirow[t]{2}{*}{ Other/missing values } & $7(2 \%)$ & 200-399 & $77(26 \%)$ \\
\hline & & $>400$ & $56(19 \%)$ \\
\hline Location $^{1}$ & & Other/missing values & $6(2 \%)$ \\
\hline$\overline{\text { Urban }}$ & $163(54 \%)$ & & \\
\hline Rural & 132 (44\%) & $\underline{\text { Teaching status }}$ & \\
\hline \multirow[t]{2}{*}{ Other/missing values } & $7(2 \%)$ & Major teaching hospital & $64(21 \%)$ \\
\hline & & Minor teaching hospital & $92(31 \%)$ \\
\hline Percentage of employed physicians & & Nonteaching hospital & $141(47 \%)$ \\
\hline$<5 \%$ & $63(21 \%)$ & Other/missing values & $5(2 \%)$ \\
\hline $6 \%-15 \%$ & 57 (19\%) & & \\
\hline $16 \%-35 \%$ & $40(13 \%)$ & Ownership status & \\
\hline $36 \%-65 \%$ & 57 (19\%) & For-profit hospital & $39(13 \%)$ \\
\hline$>66 \%$, but not $100 \%$ & $58(19 \%)$ & Non-profit hospital & $226(75 \%)$ \\
\hline $100 \%$ - closed system ${ }^{2}$ & $21(7 \%)$ & Public hospital & $31(10 \%)$ \\
\hline Other/missing values & $6(2 \%)$ & Other/missing values & $6(2 \%)$ \\
\hline
\end{tabular}

\footnotetext{
${ }^{1}$ Hospitals from 47 states participated in the study.

${ }^{2}$ The 21 hospitals reporting closed systems (all employed physicians) were deleted from the analysis of hospitals reporting on non-employed physicians, leaving $n=281$ for this sample.

Note: Numbers represent frequency, followed by the percentage (rounded) of the sample in parentheses.
}

Table 2: Measurement model statistics.

\begin{tabular}{|c|c|c|c|c|}
\hline Construct & Indicator & $\begin{array}{c}\text { Loadings }(\lambda) \\
\text { Emp / Non-Emp }\end{array}$ & $\begin{array}{c}t \text { value } \\
\text { Emp / Non-Emp }{ }^{1}\end{array}$ & $\begin{array}{c}\text { Reliability } \\
\text { Emp / Non-Emp }\end{array}$ \\
\hline \multirow[t]{3}{*}{ EMR Use } & E1 & $0.78 / 0.81$ & $-{ }^{\mathrm{a}}$ & $0.76 / 0.77$ \\
\hline & E2 & $0.77 / 0.78$ & 8.89/9.41 & \\
\hline & E3 & $0.58 / 0.59$ & 8.30/8.46 & \\
\hline \multirow[t]{4}{*}{ Information Sharing } & IS2 & $0.75 / 0.70$ & $-{ }^{\mathrm{a}}$ & $0.90 / 0.87$ \\
\hline & IS3 & $0.83 / 0.75$ & $14.75 / 11.53$ & \\
\hline & IS4 & $0.88 / 0.84$ & $15.70 / 12.68$ & \\
\hline & IS5 & $0.88 / 0.86$ & 15.64/12.92 & \\
\hline \multirow[t]{3}{*}{ Shared Values } & SV1 & $0.84 / 0.81$ & $-{ }^{\mathrm{a}}$ & $0.86 / 0.88$ \\
\hline & SV2 & $0.87 / 0.91$ & $17.08 / 16.76$ & \\
\hline & SV3 & $0.76 / 0.80$ & $14.59 / 14.94$ & \\
\hline Physicians’ & PP1 & $0.66 / 0.64$ & $-{ }^{\mathrm{a}}$ & $0.90 / 0.87$ \\
\hline \multirow[t]{3}{*}{ Performance } & PP2 & $0.89 / 0.88$ & $13.24 / 11.69$ & \\
\hline & PP3 & $0.88 / 0.84$ & $13.10 / 11.40$ & \\
\hline & PP4 & $0.86 / 0.81$ & $12.83 / 11.07$ & \\
\hline
\end{tabular}

1) Values for the employed physician sample precede the values for the non-employed physician sample (E/NE).

2) Model fit (unconstrained): $X^{2}=324.36, \mathrm{df}=182, X^{2} / \mathrm{df}=1.78$, GFI=0.94; CFI=0.97, NNFI=0.96, RMSEA=0.037. Model fit (emp, $n=302$ ): $X^{2}=147.25$, $\mathrm{df}=91, X^{2} / \mathrm{df}=1.62$, GFI=0.94, CFI=0.98, NNFI=0.97, RMSEA=0.045.

Model fit (non-emp, $n=281$ ): $X^{2}=177.11$, d.f. $=91, X^{2} /$ d.f. $=1.95$, GFI=0.93, CFI=0.96, NNFI=0.95, RMSEA=0.058.

3) Teaching status and bed size included in the model as control variables.

4) Models were te sted for measurement invariance and shown to be invariant $\left(\Delta X^{2}=6.22, \mathrm{df}=10, p=0.80\right)$.

5) ${ }^{\mathrm{a}}$ Fixed parameter. 
Table 3a: Variable descriptive statistics, average variance extracted (AVE), and correlations for variables measuring employed physicians $(n=302)$.

\begin{tabular}{|c|c|c|c|c|c|c|}
\hline & 1 & 2 & 3 & 4 & 5 & 6 \\
\hline $\begin{array}{l}\text { 1. EMR Use } \\
\mu=3.91 ; \sigma=0.91\end{array}$ & $.51 / .72$ & & & & & \\
\hline $\begin{array}{l}\text { 2. Info Sharing } \\
\mu=4.16 ; \sigma=0.60\end{array}$ & .128 & $.70 / .84$ & & & & \\
\hline $\begin{array}{l}\text { 3. Shared Values } \\
\mu=4.25 ; \sigma=0.57\end{array}$ & .156 & .646 & $.68 / .82$ & & & \\
\hline $\begin{array}{l}\text { 4. Physicians' Perform } \\
\mu=4.32 ; \sigma=0.56\end{array}$ & . 162 & .588 & .639 & $.69 / .83$ & & \\
\hline $\begin{array}{l}\text { 5. Teaching Status } \\
\mu=0.74 ; \sigma=0.79\end{array}$ & .083 & .027 & . 118 & .066 & -- & \\
\hline $\begin{array}{l}\text { 6. Bed Size } \\
\mu=3.17 ; \sigma=1.32\end{array}$ & . 156 & .001 & .015 & -.045 & .550 & -- \\
\hline
\end{tabular}

1. The AVE for each variable is shown on the diagonal immediately followed by the square root of the AVE for discriminant validity testing.

2. Teaching Status and Bed Size used as controls. Teaching Status is categorical.

3. Correlations $\geq 0.588$ are significant at $\mathrm{p}<0.01$; correlations $\geq 0.156$ are

significant at $\mathrm{p}<0.05$; correlations $\geq 0.128$ are significant at $\mathrm{p}<0.10$.

Table 3b: Variable descriptive statistics, average variance extracted (AVE), and correlations for variables measuring non-employed physicians $(n=281)$.

\begin{tabular}{|c|c|c|c|c|c|c|}
\hline & 1 & 2 & 3 & 4 & 5 & 6 \\
\hline $\begin{array}{l}\text { 1. EMR Use } \\
\mu=3.84 ; \sigma=0.93\end{array}$ & $.54 / .73$ & & & & & \\
\hline $\begin{array}{l}\text { 2. Info Sharing } \\
\mu=3.83 ; \sigma=0.69\end{array}$ & .215 & $.62 / .79$ & & & & \\
\hline $\begin{array}{l}\text { 3. Shared Values } \\
\mu=3.84 ; \sigma=0.73\end{array}$ & -.009 & .501 & $.71 / .84$ & & & \\
\hline $\begin{array}{l}\text { 4. Physicians' Perform } \\
\mu=3.82 ; \sigma=0.64\end{array}$ & .156 & .652 & .601 & $.64 / .80$ & & \\
\hline $\begin{array}{l}\text { 5. Teaching Status } \\
\mu=0.70 ; \sigma=0.76\end{array}$ & .004 & .000 & .056 & .004 & -- & \\
\hline $\begin{array}{l}\text { 6. Bed Size } \\
\mu=3.15 ; \sigma=1.26\end{array}$ & . 105 & -.051 & -.083 & -.075 & .519 & -- \\
\hline
\end{tabular}

1. The AVE for each variable is shown on the diagonal immediately followed by the square root of the AVE for discriminant validity testing.

2. Teaching Status and Bed Size used as controls. Teaching Status is categorical.

3. Correlations $\geq 0.215$ are significant at $\mathrm{p}<0.01$; correlations $\geq 0.156$ are significant at $\mathrm{p}<0.05$. 
Table 4: SEM results for direct and indirect effects.

\begin{tabular}{|c|c|c|c|c|c|c|}
\hline \multirow[b]{2}{*}{ Hypotheses } & \multicolumn{3}{|c|}{$\frac{\text { Employed Physicians }}{(n=302)}$} & \multicolumn{3}{|c|}{$\frac{\text { Non-employed Physicians }}{(n=281)}$} \\
\hline & $\begin{array}{c}\text { Direct } \\
\text { effect }\end{array}$ & $\begin{array}{c}\text { T- } \\
\text { stat }\end{array}$ & $\begin{array}{c}\text { Indirect } \\
\text { effect }\end{array}$ & $\begin{array}{c}\text { Direct } \\
\text { effect }\end{array}$ & $\begin{array}{c}\text { T- } \\
\text { stat }\end{array}$ & $\begin{array}{c}\text { Indirect } \\
\text { effect }\end{array}$ \\
\hline EMR use $\rightarrow$ Info Sharing & .03 & 0.49 & -- & $.22 * * *$ & 3.34 & -- \\
\hline Info Sharing $\rightarrow$ Physicians’ Perf & $.30 * * *$ & 4.11 & -- & $.45 * * *$ & 5.83 & -- \\
\hline EMR use $\rightarrow$ Shared Values & $.15^{* *}$ & 2.19 & -- & -.01 & -0.13 & -- \\
\hline Shared Values $\rightarrow$ Physicians’ Perf & $.43 * * *$ & 5.50 & $.20 * * *$ & $.38 * * *$ & 5.44 & $.23 * * *$ \\
\hline EMR use $\rightarrow$ Physicians’ Perf & .07 & 1.24 & $.10 * *$ & .07 & 1.19 & $.09 *$ \\
\hline Shared Values $\rightarrow$ Info Sharing & $.64 * * *$ & 9.58 & -- & $.50 * * *$ & 7.19 & -- \\
\hline
\end{tabular}

Model fit (emp): $X^{2}=158.45$, d.f. $=97, X^{2} /$ d.f. $=1.63$, GFI $=0.94$, RMSEA=0.046, CFI=0.98, NNFI $=0.97$

Model fit (non-emp): $X^{2}=185.79$, d.f. $=97, X^{2} /$ d.f. $=1.92, \mathrm{GFI}=0.93$, RMSEA $=0.057$, CFI $=0.96, \mathrm{NNFI}=0.95$

${ }^{* * *} p<0.01 ; * * p<0.05, * p<0.10$.

The .09 indirect effect shown in non-employed physicians is significant at $p=.064$.

Figure 1: Research model.

H1: Weak Agent - Principal Relationship Pathway; Non-Employed Physicians (EMR - Info Sharing - Phy Performance)

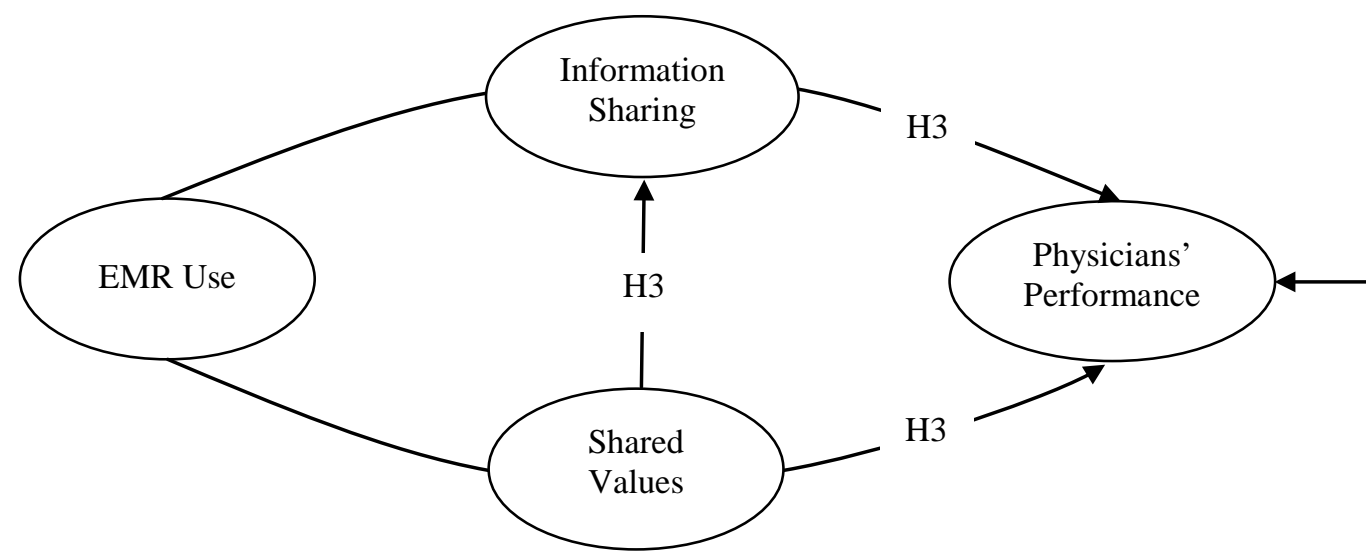

Teaching Status \& Bed Size (controls)

H2: Strong Agent - Principal Relationship Pathway; Employed Physicians

(EMR - Shared Values - Phy Performance) 
Figure 2: Significant paths in the non-employed physician sample $(n=281)$. (Solid lines indicate direct effects, dashed lines indicate indirect effects.)

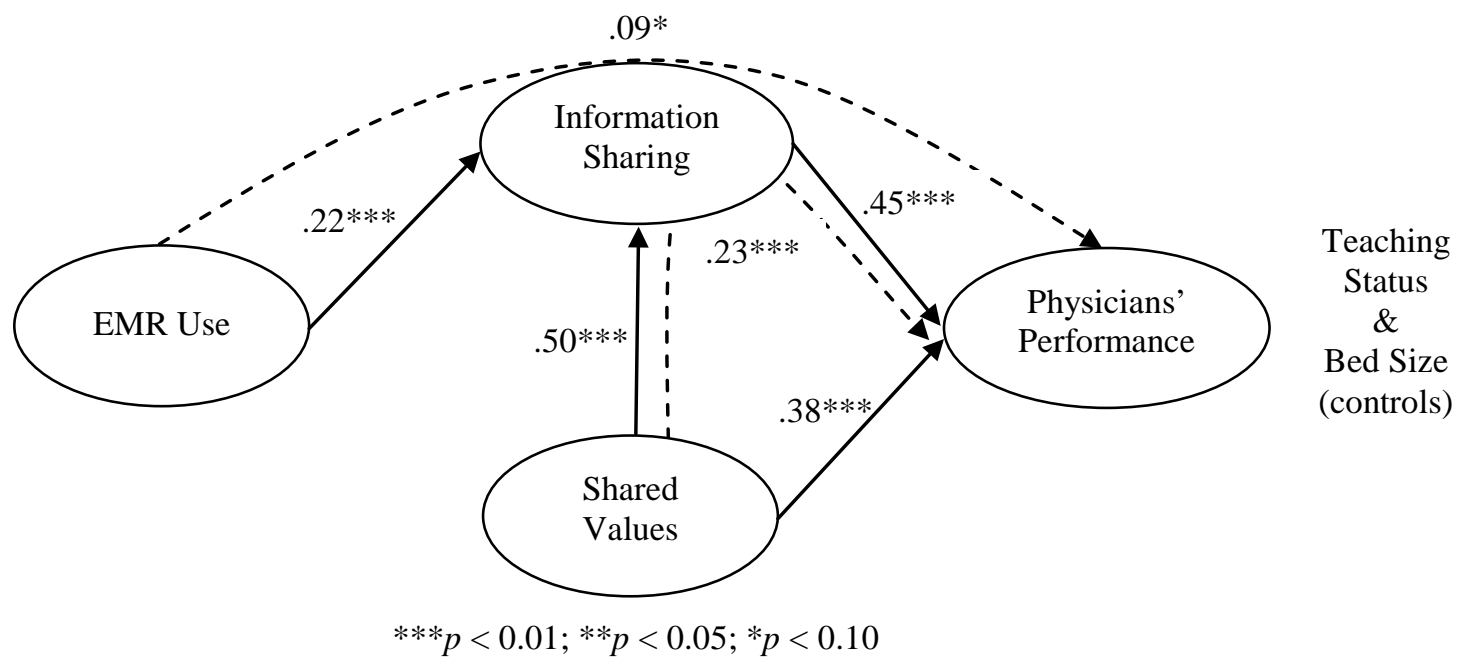

Figure 3: Significant paths in the employed physician sample $(n=302)$. (Solid lines indicate direct effects, dashed lines indicate indirect effects.)

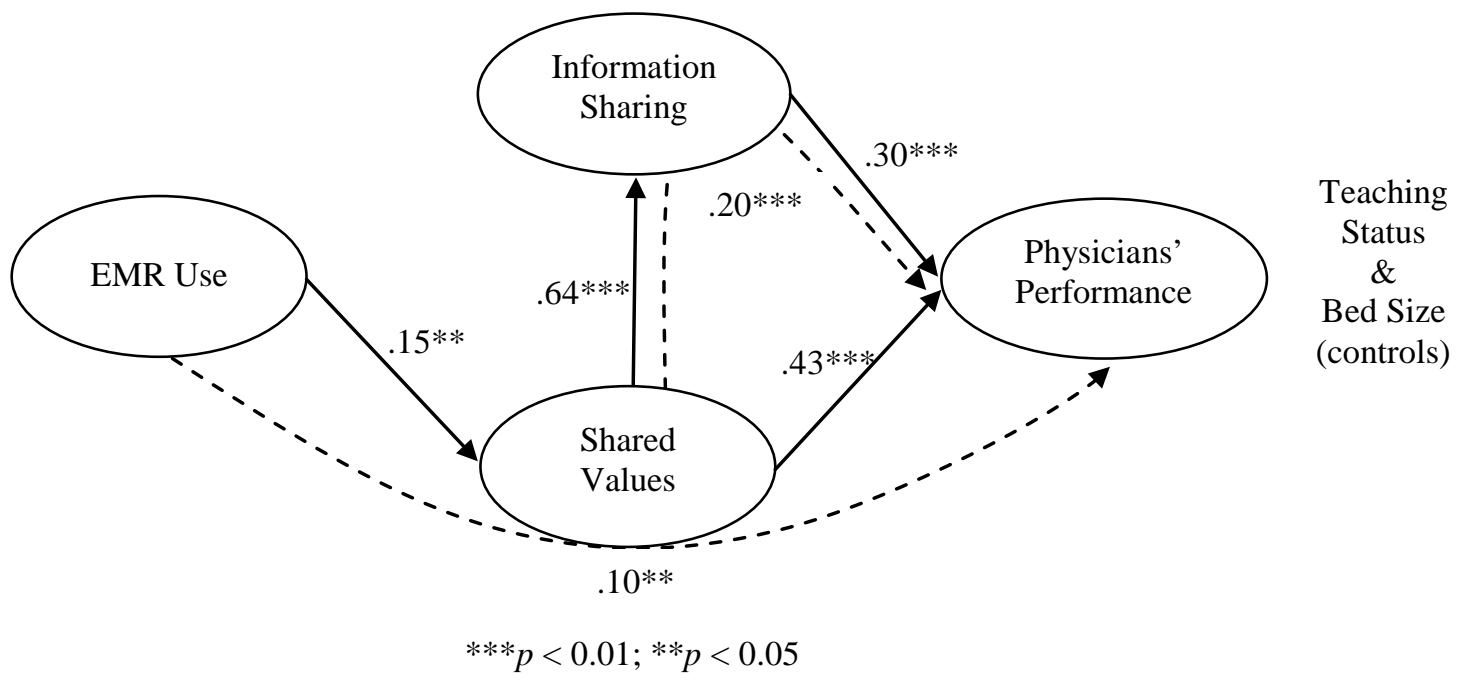

